\title{
Men of astronomy
}

\author{
Revolutionaries of the Cosmos: The \\ Astro-Physicists \\ by Ian Glass \\ Oxford University Press: 2006. 336 pp. \\ $\$ 74.50, £ 35$
}

\section{J.D. Fernie}

As a youth, Ian Glass was inspired by Eric Temple Bell's book Men of Mathematics (Simon \& Schuster, 1937), which profiled more than 30 mathematicians. In Revolutionaries of the Cosmos, Glass has attempted to do much the same for astronomy. He has restricted himself to just eight subjects, and has clearly been careful in his biographical research, which he documents in detail after each chapter. There are about 30 or 40 pages per individual, which is an admirable length, as one often wants more than a brief dictionary entry but less than a full-scale biography.

The selection of individuals - Galileo, Isaac Newton, William Herschel, William Huggins, George Ellery Hale, Arthur Eddington, Harlow Shapley and Edwin Hubble - may raise a few eyebrows. Glass chose them because each "made at least one important discovery by applying the methods of physical science to astronomy ${ }^{n}$ - hence the reference in the subtitle to 'astro-physicists', with the hyphen emphasizing the historical development. Even so, the methods of physical science changed considerably over the centuries and it seems somewhat unbalanced that a book called Revolutionaries of the Cosmos contains only passing mentions of Tycho Brahe and Johannes Kepler, yet Huggins receives the full treatment in recognition of his spectroscopic achievements. And it seems that Herschel, despite his telescopic discoveries, believed for most of his life that the Sun and Moon were inhabited by living creatures. That all these people, with the exception of Galileo, came from the English-speaking world means that the book is not a balanced history of astronomy, but that obviously was not the author's intent. Researchers from non-English-speaking nations often enter the story in passing, however, providing some balance.

Glass writes dearly, interestingly and evenhandedly throughout. His opening chapters cover material that will be familiar to most readers, but he brings out details that many might be unaware of, such as the fact that Galileo received considerable support from the more progressive church officials in his confrontation with the Catholic Church. And that while Galileo held the mathematics chair at Padua University, an official mooted an increase in salary for him because he had acquired a mistress.

But it is the later chapters, mainly covering the twentieth century, that will appeal to most readers, especially those who have at least a casual knowledge of astronomical history in

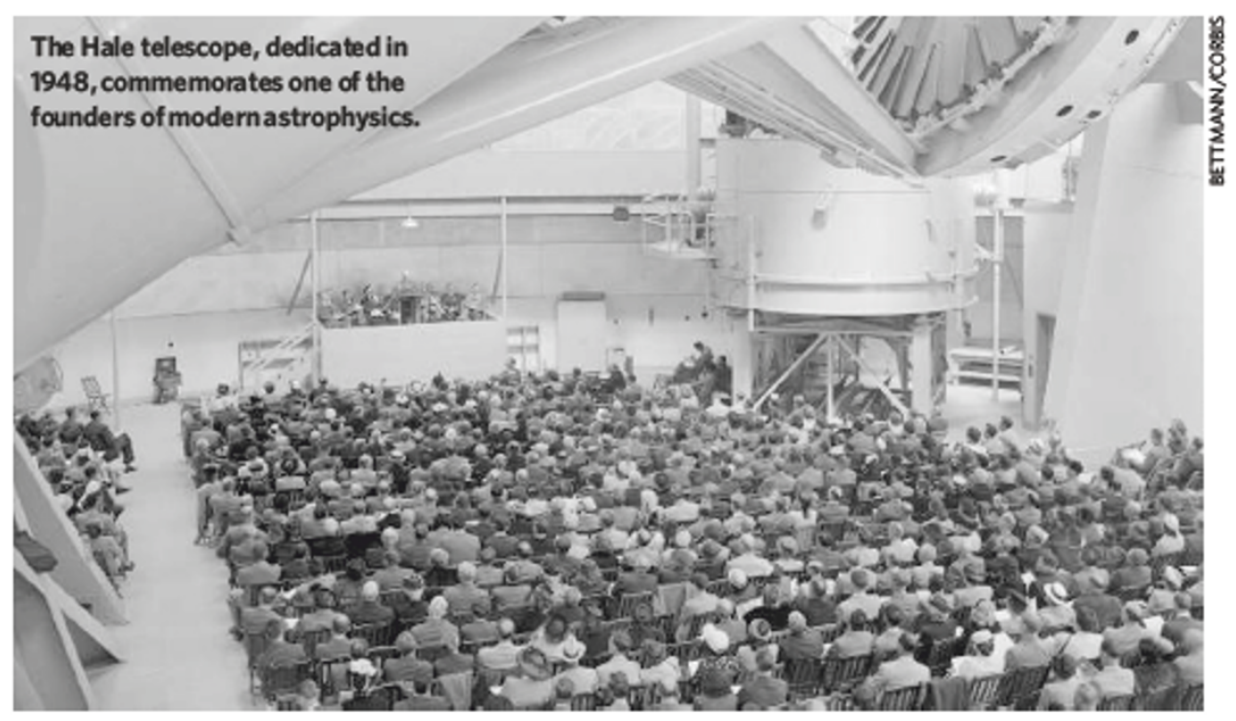

this period. The story of Hale is particularly absorbing: he founded two of the world's most important observatories, as well as the California Institute of Technology, and set up some of the world's largest telescopes, yet he battled mental-health problems for much of his life.

The chapter on Eddington is similarly fascinating. He was attacked by other British scientists around the time of the First World War because, as a Quaker, he argued that most German scientists were not the monsters they were made out to be. His pacifist views nearly led to his imprisonment by the British government. Glass also discusses Eddington's interactions with his rival, James Jeans. Their violent arguments over each other's papers presented at meetings of the Royal Astronomical Society were so intense that some people, such as G. H. Hardy, joined the society just to have a ringside seat! Yet it was a common sight to see Eddington and Jeans enjoying afternoon tea together.
Glass's writing includes quiet touches of humour here and there. For example, he tells us that early prospective authors writing for The Astrophysical Journal had to face its three editors: Hale, Gale and Frost. And that the budget for building the world's finest spectroheliograph in 1899 was so small that one of the lenses had to be bought from a pawnbroker.

Although Glass doesn't comment on it, his book does implicitly raise the question of whether or not the future will be very different. One has only to look at The Astrophysical Journal now to realize that the day of the lone researcher is over: large teams are the order of the day, and it's doubtful whether individuals will ever be as influential as they used to be. Meanwhile, Glass has written an absorbing book, which I strongly recommend. J.D. Fernie is emeritus professor in the Department of Astronomy and Astrophysics, University of Toronto, 60 St George Street Toronto, Ontario M5S 3H8, Canada.

\section{The puzzle of cooperation}

Moral Sentiments and Material Interests:

The Foundations of Cooperation in

Economic Life

edited by Herbert Gintis, Samuel Bowles,

Robert Boyd \& Ernst Fehr

MIT Press: 2005.404 pp. $\$ 50 . £ 32.95$

\section{Andrew M. Colman}

Robert May began his last presidential address to the Royal Society on 30 November 2005 by saying: "The most important unanswered question in evolutionary biology, and more generally in the social sciences, is how cooperative behaviour evolved and can be maintained in human or other animal groups and societies". For example, birds often emit alarm calls when they spot predators, but how could such behaviour have evolved? A mutant bird that never gave alarm calls would save energy and avoid the additional risk to itself while enjoying the benefits of its conspecifics' alarm calls. Its 'selfish gene' should therefore spread to fixation in the population.

For the same reason, cooperation is difficult to maintain when individuals are tempted to defect. A recent human example in Britain is the decline in voluntary take-up of the combined measles-mumps-rubella (MMR) vaccination by parents who wished to avoid an alleged health risk to their own children while 
implicitly relying on enough other children being vaccinated to maintain herd immunity'. This has the strategic structure of a social dilemma, because if all parents followed this reasoning, everyone could end up worse off than if they all behaved cooperatively.

A similar social dilemma is devastating UK fish stocks: overfishing destroyed British herring fisheries long ago and is now causing terminal decline in other fish stocks in the English Channel, the North Sea and the Baltic. Anyone who makes a living by fishing is motivated to catch as many fish as possible, because restraint is pointless if enough others are exercising restraint, and is futile if they are not. But then fish are driven to extinction and everyone is worse off than if they had all restrained themselves cooperatively.

Bill Hamilton's theory of 'inclusive fitness', or kin selection, explains the evolution of cooperation among genetically related individuals. It can explain the extreme self-sacrificing cooperation of female social Hymenoptera, who have $75 \%$ of their genes in common, but cannot explain cooperation among non-relatives. Robert Trivers's theory of reciprocal altruism shows how cooperation between non-relatives can evolve if its cost is small and is outweighed by favours returned in the future. These two theories go some way towards explaining how cooperation evolved, but neither can explain human cooperation in unrepeated interactions between strangers.

To fill this gap, Ernst Fehr and Simon Gächter introduced in 2000 a version of the theory of strong reciprocity incorporating the 'altruistic punishment' of non-cooperators. Moral Sentiments and Material Interests is devoted to their theory's biological, anthropological, economic and social ramifications and related ideas. An introductory chapter is followed by three on the behavioural ecology of cooperation, four on modelling and testing strong reciprocity, and five on reciprocity and social policy, all by researchers in the vanguards of their fields.

According to the theory, cooperation is necessary for the provision of public goods, and the punishment of non-cooperators, or freeriders, is itself a public good - a service provided for the benefit of the whole community. Such punishment is altruistic because it is costly to those who administer it, as it takes time and energy and invites retaliation. Fehr and Gächter have provided persuasive experimental evidence, reviewed in this book, that cooperation flourishes when punishment is possible and breaks down when it is not.

A problem not addressed in the book is that, because altruistic punishment is costly, natural selection should tend to eliminate it. Failure to punish defectors must presumably be treated as second-order defection, itself subject to sanctions from other group members. But what about sanctions against third-order defectors who neglect to punish second-order defectors, and so on? This is an infinite regress

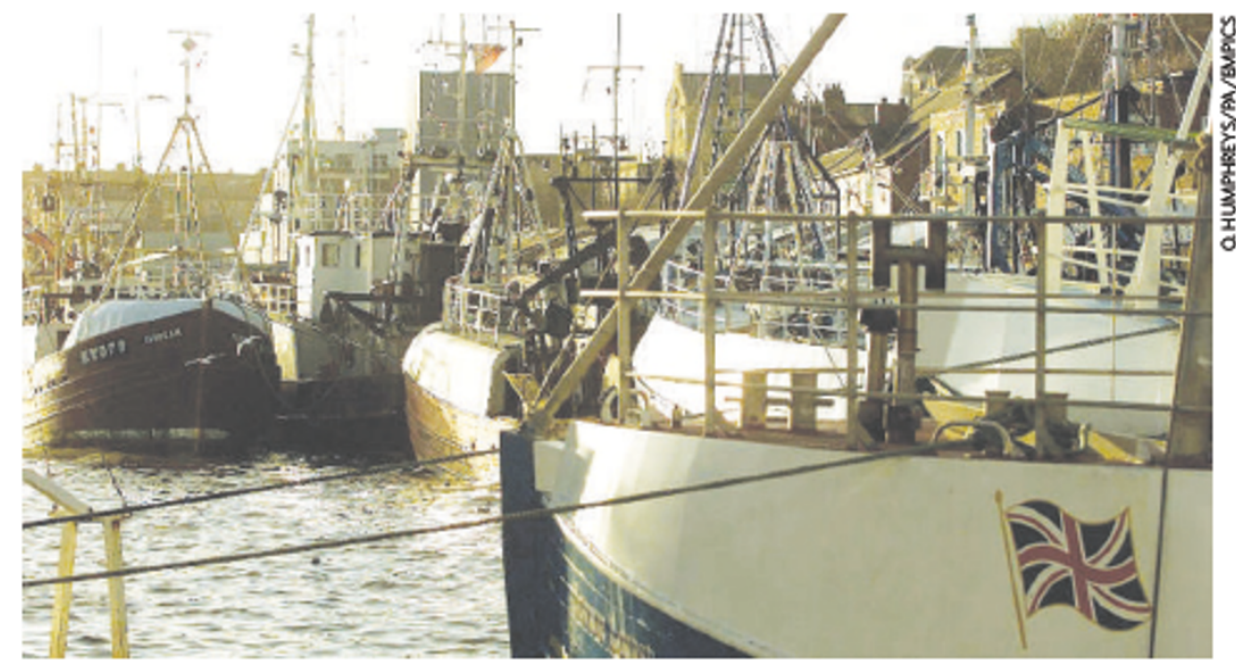

Tragic commons: North Sea fishing boats sitidle, thanks to rational economic decision-making.

that becomes less credible with the addition of each successive layer. Strong reciprocity is an important and illuminating discovery, but we seem to have replaced the problem of explaining cooperation with that of explaining altruistic punishment.

The book provides a superb interdisciplinary synthesis of cooperation as explained by strong reciprocity and associated phenomena. Other explanations of cooperation in unrepeated interactions between strangers hardly get a look in, however. The most important is Richard Alexander's theory of 'indirect reciprocity', according to which people use observations of direct reciprocity between others when deciding how to act towards them in the future. People benefit by cooperating, even in one-off encounters with strangers, because cooperation enhances one's reputation for cooperativeness and elicits reciprocal cooperation from others. This is a powerful theory, supported by evidence from computational and experimental studies, but Moral Sentiments and Material Interests mentions it only in passing. Andrew M. Colman is in the School of Psychology, University of Leicester, Leicester LE1 7RH, UK.

\section{Back to the drawing board?}

Knowing: The Nature of Physical Law
by Michael Munowitz
Oxford University Press: 2006. 432 pp

Ł19.99, \$35

\section{David Lindley}

Among the many services that Michael Faraday rendered to science was his innovation of illustrating theoretical ideas by means of pictures and diagrams. For Faraday, who knew next to no mathematics but had a powerful visual imagination, the image was the concept. But as his successors dressed his ideas in the finery of nineteenth-century mathematics, we have come to think of mathematics as the essence of theory, with pictures being merely a helpful adjunct. Attempting to push the pendulum back a little, Michael Munowitz has written an account of modern physics that Faraday might appreciate, using no mathematics (well, all right, there is some arithmetic) but plenty of illustrations. His mixed success shows, rather sadly perhaps, how far theory has moved beyond our ability to capture it in an easily grasped visual form.

Munowitz plunges in with an opening chapter devoted to the four elementary forces of nature. Gravity holds the Solar System together, and electromagnetic forces do much the same thing for atoms. Going to a still smaller scale, we see how there must be a strong nuclear force to prevent positively charged protons from bursting out of the nucleus. This is nicely done. In each case, we perceive the force through its ability to control a physical system.

But then comes the pesky weak nuclear force, or rather interaction. The change of word betrays the problem. If there is some visualizable structure that the weak interaction holds together, I can't think of it, and neither can Munowitz. Instead, he talks about radioactive decays that the weak interaction engenders and the connection to something that might be called a force is quietly dropped. I don't mean this as a criticism so much as a recognition of how difficult a task Munowitz has set himself.

Where Munowitz succeeds admirably, however, is in his recurrent emphasis on the way that principles of invariance and symmetry dictate the shape of natural law. Insistence that physics cannot depend on absolute velocity - there is no such thing - leads to the conservation law for momentum. Likewise, the impossibility of absolute time takes us (not so obviously) to the conservation of energy. In neither case can Munowitz make 